\title{
CONSTITUIÇÃO MÚLTIPLA E POTÊNCIA NA FILOSOFIA POLÍTICA DE ESPINOSA
}

Daniel Santos da Silva*

Resumo: A filosofia política de Espinosa tem uma relação direta de constituição com sua ontologia, terreno no qual o conceito de potência é definido e a partir do qual suas propriedades no campo político podem ser deduzidas em sua pluralidade. Aqui realçamos alguns dos aspectos mais importantes para nossa pesquisa atual, que foca na realidade necessária do conflito na constituição da política e nas formas como a multiplicidade pode ser avaliada teórica e praticamente na constituição e na crítica das formas políticas determinantes da sociabilidade.

Palavras-chaves: Multiplicidade, política, constituição, direito, conflito

Sem dúvida, um dos problemas mais ardilosos da filosofia espinosana, objeto de crítica desde o século XVII, e consequentemente tema constante nos escritos de seus intérpretes, está diretamente relacionado às formas pelas quais o filósofo holandês faz nascer o movimento no mundo, múltiplo, de uma unidade absolutamente infinita, a substância única. De Pierre Bayle a Hegel, de Tschirnhaus a Adorno, nas mais variadas tonalidades, o espanto ou a revolta dificultaram o acesso ao liame entre o uno e o múltiplo na ontologia de Espinosa, quase bloqueando, em grande parte das leituras até o século XX, a energia política, de notáveis caracteres revolucionários, provinda da leitura das obras políticas desse autor. Termos que na escolástica sempre cumpriram certo papel de conceitos teológicos, como ordem, direito natural, entre outros, reaparecem unidos a toda a carga produtiva - infinitamente produtiva - que tem a imanência da substância a seus efeitos, modos de realidade que, pensados do ponto de vista da singularidade, interagem nas mais diversas conexões determinadas e necessárias produzindo o que chamamos de campo político, de vida civil.

A partir daí, se levamos em consideração que a relação entre o uno e o múltiplo é uma das mais determinantes da história da filosofia, vemos aos poucos surgir com a obra de Espinosa uma nova concepção de ordem: impropriamente aplicada à totalidade e seu desenvolvimento, a ordem reaparece na diferenciação de aspectos essenciais à sua filosofia, como a distinção entre ordem imaginativa das coisas e ordem racional, ordem

\footnotetext{
* Doutor em filosofia pela Universidade de São Paulo (USP). 
temporal ou eterna, e ainda em outros momentos. No que concerne ao múltiplo e sua relação com a unidade total das coisas, a ordem instala no seio da causalidade divina a extrema necessidade de toda a realidade substancial, é a ligação entre todas as coisas particulares, é o liame entre as singularidades infinitas causadas imanentemente por Deus.

Assim, Deus produz necessariamente todas as coisas singulares com a mesma necessidade com que produz a si próprio, e essa infinita multiplicidade que marca a natureza produtiva da substância vai sendo determinada conforme Espinosa mais se aproxima dos enunciados ético-políticos de sua filosofia - a multiplicidade é pensada na vida dos homens desde seus aspectos mais constitutivos, vitais e essenciais (através da pluralidade que é a própria essência do indivíduo enquanto uma certa e determinada proporção) até relacionais, aspectos estes que mostram toda a força concreta que tem a filosofia de Espinosa na medida em que sua ética e sua política subsumem todos os pressupostos da causalidade imanente demonstrada na primeira parte da Ética e ainda desenvolvem uma nova maneira de encarar as relações entre os homens; o valor ético da multiplicidade começa já a surgir quando vemos Espinosa deslocar a consciência cartesiana de seus status substancial para a sua histórica constituição afetiva, pois que, cito Espinosa, "a mente humana não conhece o próprio corpo humano e não sabe que ele existe senão por meio das ideias das afecções pelas quais o corpo é afetado", e "a mente não conhece a si mesma senão enquanto percebe as ideias das afecções do corpo" (E, II, P19 e E, II, P23). Ou seja, qualquer pensamento, melhor, qualquer ideia que o homem possa ter de si mesmo é constituída juntamente com a vivência pelo corpo de múltiplas afecções que o relacionam ao mundo, e as ações daquele sobre este podem assim serem compreendidas como orientadas pelo desejo, desejo tanto mais complexo e plural quanto é plural o corpo humano.

Para pensar a gênese do corpo político não se sai desse campo de imanência que perpassa a ontologia e a ética, e Espinosa, levando à radicalidade no mundo humano suas concepções sobre a realidade da causalidade natural, é levado a repensar a própria concepção de política: a passagem do múltiplo ao uno, do estado de natureza ao corpo social, não se faz pela organização voluntária e racional que da dispersão natural em grande parte motivada pelo medo da morte e da dor reúne os homens sob a unidade de uma soberania legislativa; antes, Espinosa perverte a lógica contratual da união política dos homens e trabalha com os conceitos relacionados à continuidade, à produção de 
uma individualidade maior a partir de múltiplos constituintes que concorrem para a dita gênese do corpo político. Sabemos que é essa a questão que mais distancia a política hobbesiana da do filósofo holandês, pelas próprias palavras deste, escritas na carta 50: “...a diferença (entre as duas concepções de política) consiste em que mantenho sempre o direito natural e que considero que o magistrado supremo, em qualquer cidade, só tem direitos sobre os súditos na medida em que seu poder seja superior ao deles; coisa que sempre ocorre no estado natural”.

A potência daquele que exerce o cargo da soberania não se separa em nenhum dos regimes pensados por Espinosa daquela potência múltipla que atuou na constituição do corpo político, logo não se pode falar de transferência de poder neste caso - no sentido exposto acima e que implica a ruptura entre estado de natureza e estado civil -, e é necessário então recolocar as formas dos regimes políticos, seus conflitos internos e a melhor maneira de ordenar suas instituições (para remetermos a Maquiavel) a partir da perspectiva do exercício do direito natural da cidade (a verdadeira summa potestas), que enfim se identifica com a potência da multidão. Multidão para Espinosa designa essa potência una que exerce direito, e que, nas palavras de Antônio Negri, é o verdadeiro sujeito político - visão essa diametralmente oposta àquela que faz da multidão um conglomerado superposto de unidades desorganizadas entre si, e do povo a instituição da ordem por meio da transferência de poderes a uma instância superior e politicamente transcendente. De certo modo, podemos com isso afirmar que a unidade geralmente requerida pela realidade de um corpo político não encontra na filosofia de Espinosa a restrição formal do regime que funciona na cidade: mesmo que admitamos que a monarquia não pode ser tão boa quanto a democracia no que diz respeito às liberdades individuais e coletivas, e à segurança e à paz, do ponto de vista de sua constituição a potência da Cidade ainda é a potência múltipla da multidão, como nos mostra o Tratado Político, 2, XVII.

Espinosa compreende favoravelmente grande parte das análises políticas de Maquiavel e a principal referência feita a ele no Tratado Político sucede a afirmação de que numa cidade livre a esperança de vida prevalece sobre o medo da morte - não o exclui, mas apenas repõe de uma outra maneira os conflitos inerentes à constituição civil e os conecta diretamente à questão da proporcionalidade. O corpo político expressa tanto quanto um corpo humano individual - em sua complexidade própria a cada corpo, a cada constituição - uma configuração afetiva, cujas proporções relativas à potência de 
agir e de padecer desse corpo se encontram determinadas por como ele exerce sua potência e em como ela é distribuída na vida civil. Para que essa potência se exerça de forma absoluta, situação em que o corpo decisório da Civitas coincide completamente com o corpo da multidão, não é preciso a ausência de conflitos - situação que para Espinosa certamente não define a paz -, antes é necessário que o imperium seja a expressão completa da potência da multidão, e apenas a assembléia de cidadãos pode expressar isso nessa amplitude. Nela, as decisões políticas se pautam pelo que é do direito comum, da potência comum, diante da qual a potência relativa do indivíduo tende a zero (TP, II, 16). Apenas assim, vê Espinosa, haveria mecanismos institucionais suficientes para impedir completamente o tratamento da diferença como exclusão política, já que, cito Espinosa, “cada um possui tanto menos direito quanto mais todos os outros reunidos o sobrelevem em poder, isto é: cada um não tem, na realidade, sobre a natureza, senão o que lhe confere a lei comum"1.

Não precisamos aprofundar aqui o sentido - trabalhado sob mais de uma perspectiva - do conceito de lei, cuja definição detalhada encontra-se no quarto capítulo do TTP, livro que contextualiza filosófica e politicamente a constituição de um corpo político determinado, o hebreu. Nas relações entre lei e obediência, vemos Espinosa pensar a realidade jurídica de um povo nas formas constitucionais do direito enquanto potência de existir e agir, na medida em que toda a obediência civil se funda no temor e no respeito em direção ao soberano; o que é válido ressaltar é que nesse contexto de uma produção de direitos imanente à constituição múltipla da multidão a lei não pode ser entendida como um obstáculo ao direito - pensamos mais uma vez em Hobbes -, pelo contrário, ela não tem eficácia jurídica senão enquanto expressa uma potência real, ou melhor, um exercício real de potência, no caso a do soberano. Ao cortar as aparas da transcendência no campo político, Espinosa o faz pelo menos em dois níveis: coloca-se diretamente contra qualquer fonte transcendente de poder político e de sua legitimação, promovendo a decomposição da filosofia política tomista ${ }^{2}$; e igualmente desfaz a lógica hobbesiana do poder soberano transcendente (cujo um dos principais fundamentos é a dicotomia entre lei e direito). Concernente ao segundo nível, não há na filosofia política espinosana qualquer entrega plena da potência própria, ou seja, do direito natural próprio, já que nenhuma vontade e nenhum raciocínio podem cair totalmente sob jurisdição alheia ${ }^{3}$. Em última instância, apenas a distinção hobbesiana (para não citarmos a origem divina do poder vigente no medievo) entre a multidão e o soberano 
podem fundar um direito absoluto deste na prática descolado da potência - que em termos de ação política quase permanece virtual - da multidão.

O imperium é, pois, a potência da multidão e é o comum que deve guiar a coisa pública; o comum resgata a multiplicidade constitutiva do corpo político - o que faz Espinosa combater a ideia corriqueira de que os conflitos que pululam na democracia sejam sinal de falência institucional; vemos, pelo contrário, Espinosa reafirmar a riqueza da multiplicidade simultânea agora na esfera do corpo político: quanto mais um corpo político consegue ser afetado por diferentes afetos, sem perder a sua forma, mais ele é definido pela vitalidade, pela força das paixões alegres, mais se define pela liberdade e pela esperança de vida. A forma do político pressupondo o concurso de múltiplas singularidades, as determinações relativas à saúde das cidades fícam direcionadas para as configurações dessa multiplicidade, a democracia sendo a organização em que menos se tem a exclusão do plural, vivendo o múltiplo como afirmação de liberdade e de vida.

Por outro lado, enquanto a causalidade natural trabalhada no corpo político na filosofia de Espinosa cria condições para que pensemos na relevância do comum em relação com a saúde desse mesmo corpo na forma de uma multiplicidade constitutiva, sem rupturas entre a potência da multidão e as decisões políticas, o campo de atividade dessa mesma multidão é ampliado e as liberdades políticas conquistadas nesse processo passam a integrar a proporção que define a cidade; se é a esperança de vida comum que determina os interesses comuns, a cidade é mais livre, porque mais determinada a agir conforme a natureza que a define. A inteligibilidade da política espinosana repousa também sobre o fato de que, segundo o TP, III, 6, "a razão nada ensina que seja contra a natureza", logo uma "razão sã não pode ordenar que cada um dependa exclusivamente de si mesmo enquanto os homens estiverem sujeitos a paixões...". Sob este aspecto, compreende-se em que sentido a gênese do corpo político faz apelo a uma complexidade afetiva que acaba envolvendo o medo e a esperança em suas correlações proporcionais, e como a meditação política sobre a liberdade é inseparável da compreensão dos processos produtivos do comum em meio à grande multiplicidade de interesses e engenhos que concorrem para a vida civil.

O homem age sempre tendo em vista seus interesses próprios, e isso está pressuposto na produção política do comum. Sempre, reflete Espinosa, o homem age 
segundo as leis de sua natureza e por isso prioriza seu interesse - sempre, neste contexto, significa tanto no estado de natureza como no civil; “... em cada um destes dois estados é a esperança ou o temor que leva o homem a fazer isto ou aquilo, e a principal diferença entre os dois estados é que, no estado civil, todos têm os mesmos temores e a regra de vida é comum, o que não suprime, necessariamente, a faculdade de julgar, própria de cada um." Com efeito, é por interesse próprio que cada um decide obedecer às ordens da cidade - seja por temor ou por amor à tranquilidade, essa obediência responde a uma operação política constituinte, não excessivamente passiva como entendemos que seja a obediência dentro dos parâmetros judaico-cristãos ou mesmo dos do jusnaturalismo moderno.

Assim, quando fomos levados a pesquisar as relações entre resistência política e a "estrutura" conflitiva que é exigida pela inteligibilidade da filosofia política de Espinosa, passamos a rever a própria constituição do corpo político, e conectar, a partir disso, essa potência "una" e sua perseverança no ser à sua abertura democrática para a multiplicidade. A democracia é necessariamente o mais absoluto dos regimes justamente por abrigar, em sua configuração espinosana, tensões sem as quais os homens afastam-se da vida civil e aproximam-se da solidão.

Um intérprete italiano da filosofia de Espinosa, Vittorio Morfino, tem uma forte reflexão sobre o papel constitutivo da pluralidade na formação do campo político em Espinosa, e procura evidenciar o quanto a constituição do político em momento nenhum implica a homogeneização dessa pluralidade e de suas diversas operações dentro de um mesmo corpo. Para ele, toda a compreensão das durações singulares se dá em termos relacionais, e a potentia multitudinis, singular em sua realidade, plural em sua constituição, é campo de múltiplas temporalidades para as quais não é possível encontrar um referencial absoluto. Essa abordagem do autor italiano parte da premissa, cremos, de que a multidão e sua potência são as peças-chave para a compreensão do que é a atividade política para Espinosa, ponto do qual igualmente se parte para que possamos indagar de que maneiras as resistências individuais e coletivas do campo político respondem a conflitos essenciais, constitutivos de qualquer império político que tenha verdadeiramente como finalidade a paz e a segurança de todos, e não a concreção de desejos individuais cujas potências se exercem de modo excludente - o que a monarquia e a aristocracia não conseguem realizar, a não ser aproximadamente 
conforme as análises e a propostas de abertura democráticas feitas por Espinosa no Tratado Político.

É com base nesses mesmos pressupostos que podemos entender a defesa da liberdade de pensamento e de juízo realizada pelo filósofo holandês. Longe de ser uma defesa baseada em princípios utópicos, ou uma política produzida a partir de noções universais e abstratas sobre a natureza humana, as reflexões e críticas de Espinosa criam um terreno de profusão constituinte sem estabelecimento de uma hierarquia estruturante; em outras palavras, e não por outra razão tantos contemporâneos resgatam essas idéias no momento de compreender as formas políticas hoje extremamente complexas e atuantes, da filosofia política de Espinosa não apenas se extrai a relevância de compreender o conflito como parte constitutiva da liberdade pública - virtude política -, mas também modos de desmantelamento, se assim podemos nos expressar, dos discursos que buscam fundar a paz e a liberdade como contrários à segurança e à virtude. Muitos desses discursos, filosóficos ou não, aplicam à liberdade individual, inalienável, de juízo e crítica, a censura provinda de uma falsa necessidade de homogeneização dos singulares e de suas potências, em nome da segurança de todos. Assim, longe de erradicar os conflitos nocivos à vida civil, o discurso e a prática política que separam "substancialmente" o poder soberano da multiplicidade inerente à constituição do civil apenas camuflam ou procuram camuflar todos os conflitos, mesmo aqueles essenciais à saúde civil.

Este texto apenas remarca alguns dos pontos mais fulcrais que guiam nossa atual pesquisa. Bem distante de darmos conta dos principais conflitos que emergem dessa necessária constituição plural e potente do político, apontamos nada mais que alguns critérios de análise e de crítica que nos ajudam não somente a prosseguir na pesquisa, mas a pensar as realidades políticas contemporâneas.

\section{MULTIPLE CONSTITUTION AND POTENCY IN SPINOZA'S POLITICAL PHILOSOPHY}

The political philosophy of Spinoza has a direct relationship with its ontologic constitution, land on which the concept of power is defined and from which its properties in the political field can be deduced in its plurality. Here we highlight some of the most important in our current research, which focuses on the necessary reality of the conflict in the formation of politic and 
the ways in which the multiplicity can be evaluated theoretically and practically in the constitution and in the critical determinants of political forms of sociability aspects.

Keywords: Multiplicity, politics, constitution, law, conflict

\section{REFERÊNCIAS BIBLIOGRÁFICAS}

1. ESPINOSA, B. de. Tratado Teológico-Político. Trad. De Diogo Pires Aurélio. São Paulo: Martins Fontes, 2003.

2 . Ética, demonstrada em ordem geométrica. Trad. Grupo de Estudos do séc. XVII - USP, coordenação de Marilena Chauí. Em preparação. 3. Tratado Político, Trad. Manuel de Castro. São Paulo: Ed. Nova Cultural, 1997

4. Correspondências. Trad, Marilena Chaui. São Paulo: Ed. Nova Cultural, 1997.

5. MATHERON, A. Anthropologie et politique au XVII siècle. Études sur Spinoza. Paris: J. Vrin, 1986.

6. MORFINO, V. Spinoza e il non contemporaneo. Verona: Ombre Corte, 2009.

\section{NOTAS}

\footnotetext{
${ }^{1} \mathrm{TP}, 2$, XVI.

${ }^{2}$ Cf. principalmente o primeiro artigo de Matheron do livro que consta nas referências bilbiográfica: "Spinoza et La décomposition de La politique thomiste: Machiavélisme et Utopie".

3 TTP, XX: "A vontade de um homem não pode estar completamente sujeita a jurisdição alheia, porquanto ninguém pode transferir para outrem, nem ser coagido a tanto, o seu direito natural ou a sua faculdade de raciocinar livremente e ajuizar sobre qualquer coisa".
} 